\title{
CEREBRO-VASCULAR ACCIDENTS IN HEMODIALYSIS PATIENTS: A RETROSPECTIVE STUDY IN AMERIKAN HOSPITAL
}

\author{
Fjona Nasto1*, Arjeta Dedej ${ }^{1}$, Denada Haxhiu ${ }^{1}$, Nestor Thereska ${ }^{1}$ \\ ${ }^{1 *}$ American Hospital, Tirana, Albania; \\ *Corresponding author Fjona Nasto, e-mail: fnasto@ spitaliamerikan.com;
}

Received December 2019; Accepted January 2020; Published February 2020;

DOI: https://doi.org/10.31407/ijees10.125

\begin{abstract}
In 2010, strike was globally the second commonest cause of death and the third commonest cause of life years lost due to premature mortality. Stroke is the leading cause of neurological disability worldwide and the suffering, negative consequences to patients, careers and society as a whole are incalculable. Chronic Renal Disease and (CRD) end-stage Renal Disease (ESRD) are associated with an increased risk of stroke. The three CRD, ESRD, and stroke are associated with premature death, cognitive impairment, dementia and decreased quality of life. Due to ageing populations in hemodialysis and comorbidities mortality rate of stroke in hemodialysis is very high. Patients with CRD are more predisposed to suffer severe and recurrent strokes. For every $10 \mathrm{ml} / \mathrm{min} / 1.73 \mathrm{~m}^{2}$ reduction in glomerular filtration rate (GFR) the risk of stroke increases by $7 \%$. CRD and stroke are sharing cardiovascular risk factors. Traditional atherosclerotic risk factors for CVA, such as age, hypertension diabetes mellitus, and dyslipidemia are common in dialysis patients, there also are risk factors to the uremic process, predisposing hemodialysis patients to either ischemic or hemorrhagic stroke. The aim of our study is to highlight the link between stroke and factors like albumin, haemglobine, cholesterol, calcium levels, the type of vascular access and high mortality rate.
\end{abstract}

Key words: dialysis, stroke, risk factors, mortality 